\title{
GAPDH binds to active Akt, leading to Bcl-xL increase and escape from caspase-independent cell death
}

\author{
MA Jacquin ${ }^{1,2}$, J Chiche ${ }^{1,2}$, B Zunino ${ }^{1,2,3}$, M Bénéteau $^{1,2}$, O Meynet $^{1,2}$, LA Pradelli ${ }^{1,2}$, S Marchetti $^{2,4}$, A Cornille ${ }^{1,2}$, M Carles $^{1,3}$ \\ and J-E Ricci ${ }^{\star, 1,2,3}$
}

Increased glucose catabolism and resistance to cell death are hallmarks of cancers, but the link between them remains elusive. Remarkably, under conditions where caspases are inhibited, the process of cell death is delayed but rarely blocked, leading to the occurrence of caspase-independent cell death (CICD). Escape from CICD is particularly relevant in the context of cancer as apoptosis inhibition only is often not sufficient to allow oncogenic transformation. While most glycolytic enzymes are overexpressed in tumors, glyceraldehyde-3-phosphate dehydrogenase (GAPDH) is of particular interest as it can allow cells to recover from CICD. Here, we show that GAPDH, but no other glycolytic enzymes tested, when overexpressed could bind to active Akt and limit its dephosphorylation. Active Akt prevents FoxO nuclear localization, which precludes Bcl-6 expression and leads to $\mathrm{Bcl}-\mathrm{xL}$ overexpression. The GAPDH-dependent $\mathrm{Bcl}-\mathrm{xL}$ overexpression is able to protect a subset of mitochondria from permeabilization that are required for cellular survival from CICD. Thus, our work suggests that GAPDH overexpression could induce $\mathrm{Bcl}-\mathrm{xL}$ overexpression and protect cells from $\mathrm{CICD}$-induced chemotherapy through preservation of intact mitochondria that may facilitate tumor survival and chemotherapeutic resistance.

Cell Death and Differentiation (2013) 20, 1043-1054; doi:10.1038/cdd.2013.32; published online 3 May 2013

Cancer cells are diverse in origin, but they share some features, including escape mechanisms from cell death and increased glucose metabolism (Warburg effect ${ }^{1-3}$ ). Most physiological cell deaths in animals occur by apoptosis, and most apoptosis in mammals occurs through the mitochondrial pathway. ${ }^{4}$ In the simplest description of the mitochondrial pathway, signals that elicit apoptosis activate the pro-apoptotic members of the Bcl-2 family to form pores in the outer membrane of the mitochondria. The anti-apoptotic members of the family prevent this event and thereby block apoptosis. ${ }^{5,6}$ Mitochondrial outer membrane permeabilization (MOMP) allows holocytochrome $c$ to diffuse out. It interacts with Apaf-1, resulting in caspase- 9 activation, leading to activation of the executioner caspases-3 and -7 , which then orchestrate apoptosis by cleaving specific substrates within the cell. ${ }^{7}$

Shortly after caspases were identified as the enzymes that orchestrate apoptotic cell death, it became apparent that inhibition of caspase activity may not necessarily preserve cell survival, even if the processes of apoptosis are effectively blocked. ${ }^{8}$ Indeed, numerous reports described in vitro and also in vivo that complete caspase inhibition is not able to prevent cells from dying. ${ }^{8-12}$ Importantly, a deficiency of Bax and Bak will prevent MOMP and cell death. ${ }^{13}$ In general, dying cells under the conditions described above do not resemble cells dying by apoptosis, and accordingly, this form of cell death has been called caspase-independent cell death
(CICD) to distinguish it from caspase-dependent apoptotic morphology. ${ }^{14}$

The relevance of CICD is of particular interest in the context of cancer as several studies have described that apoptosis can be blunted in those pathologies (for a review, see Pradelli et al. $\left.{ }^{6}\right)$. However, as CICD is known to be as efficient as apoptosis in preventing oncogenic transformation, and as one death stimulus is able to induce apoptosis and CICD in parallel, this led to the conclusion that transformed cells and cells resistant to chemotherapeutic treatment were able to simultaneously escape both types of cell death.

Experiments performed in vivo using $\mathrm{KO}$ models indicate that CICD is a cell death mechanism engaged post MOMP under conditions where caspase activation is blunted. MOMP is frequently assumed to represent the point of no return in cell death. Several lines of evidence, however, suggest that this might not always be the case. ${ }^{15,16}$ We recently established that overexpression of glyceraldehyde-3-phosphate dehydrogenase (GAPDH) could effectively protect cells from CICD downstream from MOMP, allowing clonogenic outgrowth. This study, therefore, established the glycolytic enzyme GAPDH as the first known protein able to specifically regulate CICD but not apoptosis. This makes it a very useful tool to uncover the molecular mechanisms of CICD. ${ }^{17}$

GAPDH was long thought of as a glycolytic enzyme of seemingly little interest. However, recent studies indicate that

\footnotetext{
${ }^{1}$ Inserm, U1065, Centre Méditerranéen de Médecine Moléculaire (C3M), équipe 'contrôle métabolique des morts cellulaires', Nice, France; ${ }^{2}$ Faculté de Médecine, Université de Nice-Sophia-Antipolis, Nice, France; ${ }^{3}$ Département d'Anesthésie Réanimation, Centre Hospitalier Universitaire de Nice, Nice, France and ${ }^{4}$ Inserm, U1065, Centre Méditerranéen de Médecine Moléculaire (C3M), équipe 'mort cellulaire, différentiation et cancer', Nice, France

*Corresponding author: J-E Ricci, équipe 3, Inserm, U1065, 151 Route de St Antoine de Ginestière, BP 23194, 06204 Nice Cedex 03 , France. Tel: + 33489064304 ; Fax: + 334890642 21; E-mail: ricci@unice.fr

Keywords: bcl-2 family; cell death; glycolysis; mitochondria; Warburg effect

Abbreviations: CICD, Caspase-independent cell death; GAPDH, Glyceraldehyde-3-phosphate dehydrogenase; KA, koningic acid; MOMP, Mitochondrial outer membrane permeabilization.

Received 20.7.12; revised 22.3.13; accepted 29.3.13; Edited by E Gottlieb; published online 03.5.13
} 
it is a multifunctional protein ${ }^{18,19}$ found to be overexpressed in the vast majority of human tumors. ${ }^{20}$ In this direction, we previously established in the context of chronic myeloid leukemia (CML) that a spontaneous GAPDH overexpression was participating in the resistance of tumor cells to imatinibinduced death, thereby underlining the relevance of GAPDHdependent inhibition of CICD in pathological settings. ${ }^{21}$

The phosphoinositide-3-kinase (PI3K) pathway is one of the most commonly altered signaling pathways in human cancers. $^{22}$ The best-characterized downstream effector is the Akt pathway, which is essential for cell survival and growth during development and carcinogenesis. PI3K-Akt signaling regulates cell survival in part by phosphorylating FoxOs. ${ }^{23}$ Akt kinase is frequently activated in tumors and represents one of the main drivers for Warburg effect. ${ }^{24}$ Although it is clearly understood how Akt can lead to increased glycolysis, current knowledge regarding the impact of glycolysis on Akt activity remains limited.

In this study, we establish that GAPDH overexpression stabilizes activated $\mathrm{Akt}$, resulting in $\mathrm{Bcl}-\mathrm{xL}$ overexpression and CICD resistance. We also show that this effect is mediated through protection of a pool of intact mitochondria that are required for cellular recovery.

\section{Results}

GAPDH but not enolase or phosphoglycerate kinase can stabilize active Akt and protect cells from CICD. Akt has a central role in the regulation of cell survival and proliferation. We, therefore, investigated its role in GAPDHdependent protection from $\mathrm{CICD} .^{17} \mathrm{GAPDH}$-overexpressing cells (Figure 1a and Supplementary Figure 1A) have more active Akt than controls as judged by its phosphorylation on $\mathrm{Ser}^{473}$ and by phosphorylation of some key downstream targets, FoxO1/3. This increase in Akt phosphorylation upon GAPDH expression was confirmed in the colon carcinoma cell line LS174 upon stable GAPDH overexpression (Figure $1 \mathrm{~b}$ and Supplementary Figure $1 \mathrm{~A}$ ) and also upon transient GAPDH transfection of HeLa cells (Figure 1c). Interestingly, overexpression of two other non-rate-limiting glycolytic enzymes, phosphoglycerate kinase (PGK) and enolase, was unable to induce an accumulation of phospho-Akt (Figure 1c). The ability of GAPDH but not PGK or enolase to lead to an increase in active Akt correlated closely with its ability, but not of the other enzymes, to allow clonogenic outgrowth of the cells following $\gamma$-radiation-induced CICD (Figure 1d). The ability of the GAPDHexpressing cells to survive from CICD was confirmed upon staurosporine-induced CICD (Supplementary Figure 1B) and was found not to be associated with a difference in cell proliferation (Supplementary Figure 1C). We could then establish that inhibiting GAPDH using koningic acid (KA), a specific GAPDH inhibitor, ${ }^{25,26}$ impaired its ability to stabilize phosphoAkt (Figure 1e). In the same line, partial knockdown of GAPDH was sufficient to reduce the level of $\mathrm{Ser}^{473}$ phospho-Akt (Figure 1f). Altogether, it appeared that the capacity of GAPDH but not enolase or PGK to stabilize active Akt correlated closely with the ability of this specific enzyme to protect cells from CICD.

GAPDH-dependent protection from CICD is mediated through stabilization of active Akt. To confirm the potential role of active Akt in GAPDH-dependent protection from CICD, we used a potent Akt inhibitor (Akti). As shown in Figure 2a, whereas GAPDH overexpression led to more active Akt than in control cells, the Akti very efficiently inhibited the kinase and prevented the phosphorylation of FoxO. We, therefore, investigated the impact of Akt inhibition on GAPDH-dependent protection from $\gamma$-radiation-induced CICD. Although GAPDH was protecting cells from CICD, this protective effect was lost in the presence of the Akti (Figure 2b). We verified that the Akti does not present any toxicity in clonogenic tests over time (Supplementary Figure 2A). To further support this result, a constitutively active form of Akt (myrAkt; Supplementary Figure 2B) was overexpressed. Interestingly, Akt activation was able to significantly protect cells from $\gamma$-radiation-induced CICD (Figure 2c), altogether suggesting that GAPDH-dependent stabilization of active Akt is required for survival from CICD.

To investigate if GAPDH could enhance Akt phosphorylation or prevent its dephosphorylation, we stimulated control or GAPDH-expressing cells with insulin, a canonical Akt activator. As shown in Figure 3a, whereas Akt phosphorylation rate was equivalent in both cell lines, the dephosphorylation rate was delayed in the GAPDH-expressing cells compared with the control cells, suggesting that GAPDH could stabilize phospho-Akt once produced. Importantly, activated Erk, another key survival pathway member, was not stabilized in the presence of GAPDH, indicating a specificity of the effect (Figure $3 a$ and Supplementary Figure 3). To further confirm that GAPDH could prevent Akt dephosphorylation, we stimulated control cells (Mock) and GAPDH-expressing cells with insulin for $30 \mathrm{~min}$ and incubated the cell extract at $30^{\circ} \mathrm{C}$ in order to allow endogenous cellular phosphatases to function. As shown in Figure $3 \mathrm{~b}$, the dephosphorylation rate of Akt was lower in the GAPDHexpressing cells than in the controls, further suggesting that GAPDH could limit the inactivation of Akt.

PP2A and PHLPP are known to negatively regulate Akt activity in various systems. ${ }^{27,28}$ We did not observe a modulation of the expression of those phosphatases in the GAPDH-overexpressing cells (Figure 3c), suggesting that the GAPDH-dependent stabilization of phospho-Akt is unlikely to be linked to a modulation of the expression of those enzymes.

Finally, to understand how GAPDH could limit Akt dephosphorylation, we investigated if this enzyme could bind to phospho-Akt. Therefore, 293T cells were transiently transfected with Akt and GAPDH, and co-immunoprecipitation experiments confirmed the interaction between phospho-Akt and GAPDH (Figure 3d). We extended this observation in HeLa cells by showing that the interaction between endogenous phospho-Akt and GAPDH could be observed when either GAPDH or phospho-Akt was immunoprecipitated (Figure $3 e$ ). Very interestingly, the interaction between those proteins was lost in the presence of the GAPDH-covalent inhibitor KA (Figure 3e). This loss of interaction between GAPDH and Akt correlates closely with the ability of KA to prevent phospho-Akt stabilization by GAPDH (Figure 1e). Collectively, these data show that GAPDH can bind directly or indirectly (through the formation of a complex of proteins, for example) to phospho-Akt, thereby limiting its dephosphorylation by endogenous phosphatase(s). 
a

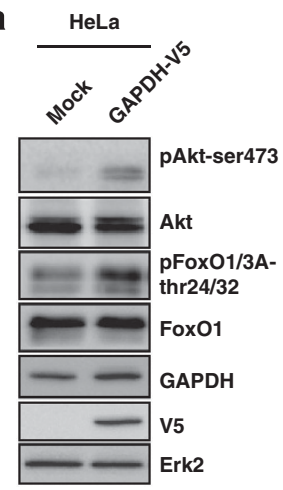

b

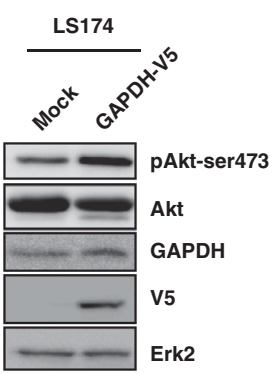

C

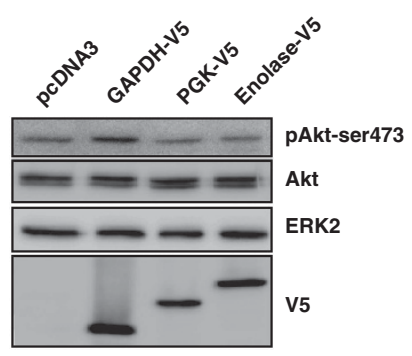

d

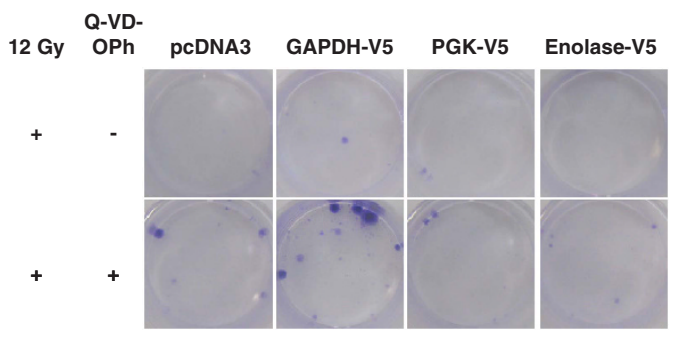

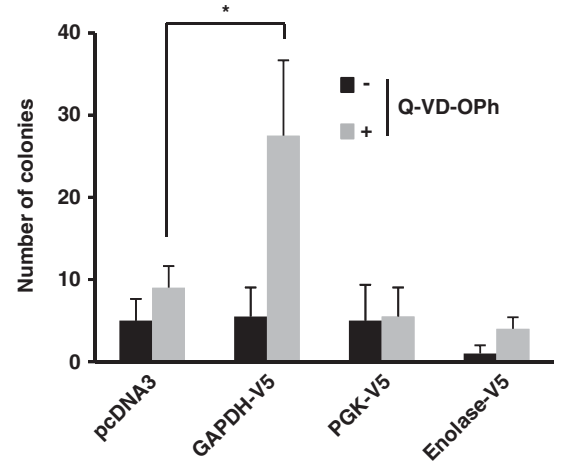

e

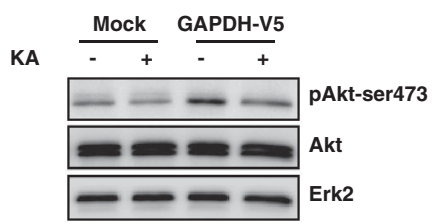

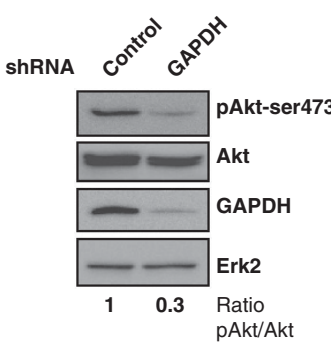

f

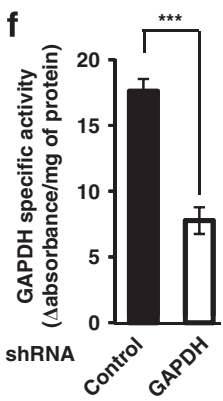

Figure 1 GAPDH overexpression induces Akt pathway activation. (a) HeLa cells stably expressing a control pCDNA $A_{3}$ vector (Mock) or a GAPDH-V5-encoding pcDNA vector were immunoblotted for the indicated proteins (phospho- or total). (b) The levels of active phospho- and total Akt, GAPDH and V5 were assessed in the LS174 cell line stably expressing a control (Mock) or a GAPDH-V5-encoding vector. (c) HeLa cells were transiently transfected with the indicated encoding vectors and immunoblotted for the indicated proteins $48 \mathrm{~h}$ later. Expression of GAPDH-V5, PGK-V5 or enolase-V5 was assed using the V5 tag (bottom panel). (d) HeLa cells were transiently transfected with an empty vector $\left(\mathrm{pcDNA}_{3}\right)$ or with $\mathrm{pcDNA} \mathrm{A}_{3}$ encoding GAPDH-V5, PGK-V5 or enolase-V5, and then irradiated as indicated \pm the caspase inhibitor Q-VD-OPh (20 $\left.\mu \mathrm{M}\right)$. The caspase inhibitor was added $30 \mathrm{~min}$ before the irradiation ( $12 \mathrm{~Gy}$ ) and replaced periodically at 48 -h intervals for 10 days. Colonies were stained with crystal violet and assessed 18 days after treatment (left panel). The number of colonies counted under each condition for four independent experiments is shown in the right panel. (e) Mock or GAPDH-V5 HeLa cells were treated with $0.5 \mu \mathrm{g} / \mathrm{ml} \mathrm{KA}$ for $6 \mathrm{~h}$ and Akt activation was assessed by immunoblots of phospho-(Ser ${ }^{473}$ ) and total Akt. (f) GAPDH specific activity (left), GAPDH protein level, and the level of active phospho- and total Akt (right) were assessed in HeLa cells transduced with either a control or an shRNA vector targeting GAPDH. The pAkt/Akt ratio was quantified and normalized to control cells. The immunoblots are representative of 3-5 independent experiments. Erk2 was used as a loading control ${ }^{\star} P<0.05,{ }^{* \star *} P<0.005$

GAPDH overexpression increases Bcl-xL levels. As MOMP is a key event in death cascades and is tightly regulated by $\mathrm{Bcl}-2$ family members, the expression of one of the most potent anti-apoptotic members, Bcl-xL, was investigated in control and GAPDH-expressing cells. HeLa cells overexpressing GAPDH showed a higher level of $\mathrm{Bcl}-\mathrm{xL}$ protein than their controls (Figure $4 \mathrm{a}$ and Supplementary Figure 4). This increase in Bcl-xL upon GAPDH overexpression was confirmed in two other cell types (LS174 (Figure 4b) and K562 cells (Figure 4c)). As shown in Figure 4, inhibition of Akt (Figure 4d) or GAPDH (Figure $4 \mathrm{e}$ ) reduced Bcl-xL expression, suggesting that GAPDH overexpression leads to increased Bcl$\mathrm{xL}$ expression in an Akt-dependent manner. To further support our conclusions, we used loss-of-function approaches. We established that Akt1/2 knockdown (Figure 4f) resulted in Bcl$\mathrm{xL}$ decrease to the same extent as that observed with the Akti (Figure 4d). As active Akt inhibits FoxO and leads to an increase in $\mathrm{Bcl}-\mathrm{xL}$ expression, we verified whether FoxO knockdown itself was leading to $\mathrm{Bcl}-6$ decrease and $\mathrm{Bcl}-\mathrm{xL}$ increase (Figure 4g).

In consistence with our results, transient expression of myrAkt in HeLa cells that protect cells from CICD (Figure 2c) 
a Mock GAPDH-V5

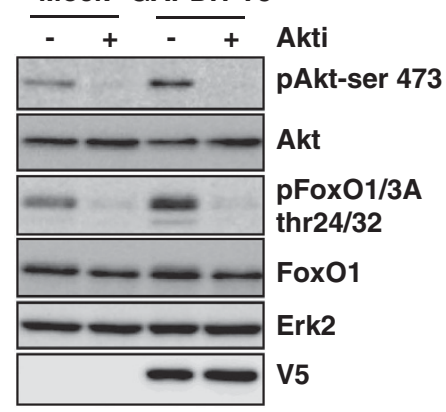

b
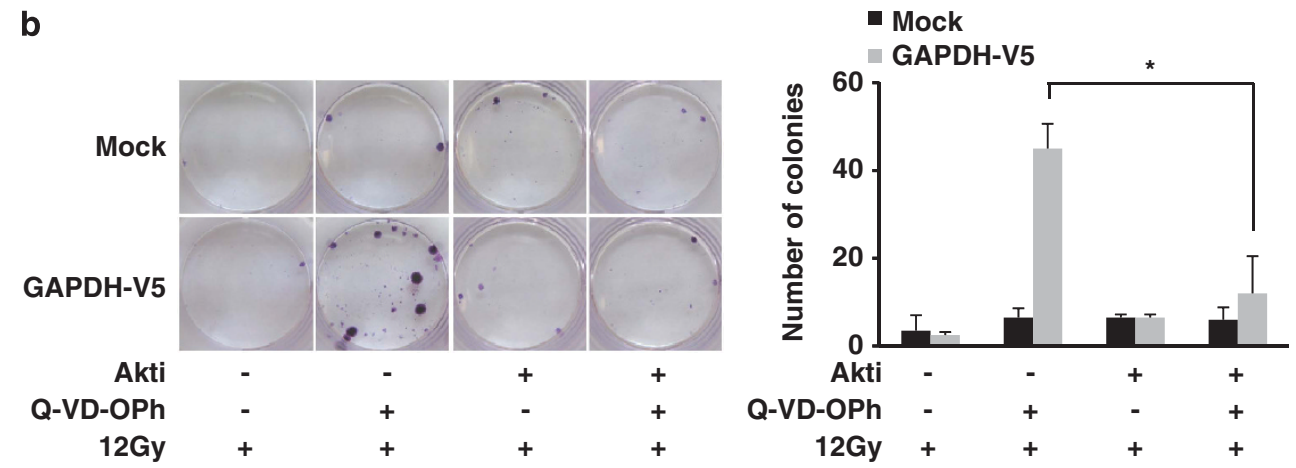

C
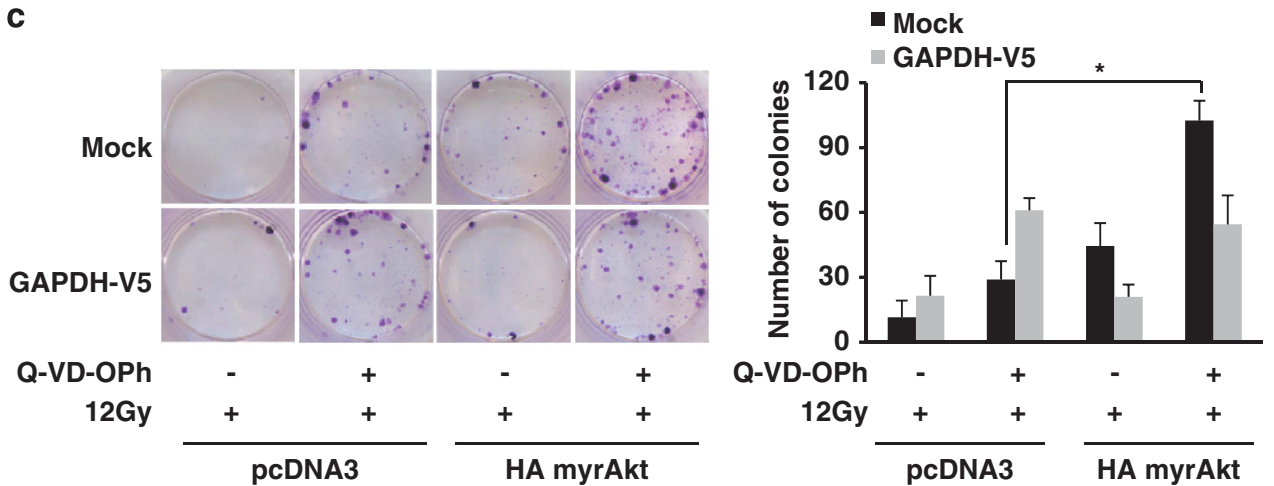

Figure 2 Akt activation is required for GAPDH-dependent protection from CICD. (a) Mock or GAPDH-V5 HeLa cells were treated with $1 \mu \mathrm{M} \mathrm{Akti}$ for $48 \mathrm{~h}$ and analyzed by immunoblot. Akt inhibition led to a decrease in phospho-Akt and phospho-FoxO as expected. (b) Mock or GAPDH-V5 HeLa cells were treated with $1 \mu \mathrm{M}$ Akti \pm the pancaspase inhibitor Q-VD-OPh (20 $\mu \mathrm{M})$. Inhibitors were added $30 \mathrm{~min}$ before a 12-Gy irradiation step and replaced periodically at 48 -h intervals for 10 days. Colonies were stained and quantified as described in Figure 1d. (c) Mock or GAPDH-overexpressing HeLa cells were transiently transfected with a constitutively active form of Akt (myrAkt) and treated $48 \mathrm{~h}$ later as described in panel $\mathbf{b}$. Typical pictures of the culture wells are shown on the left part and quantification of three independent experiments on the right part. ${ }^{*} P<0.05$. The immunoblots are representative of four independent experiments. Erk2 was used as a loading control

led to an increase in Bcl-XL protein level (Supplementary Figure 2B).

To generalize this observation further, we studied the ability of GAPDH overexpression to increase $\mathrm{Bcl}-\mathrm{xL}$ expression in primary lymphoma cells isolated from $\mathrm{E} \mu-M y c$ transgenic mice, which develop pre-B and B non-Hodgkin's lymphomas. ${ }^{29,30}$ As shown in Figure 5a, increased GAPDH expression upon transduction of primary cells led to increased $\mathrm{Bcl}-\mathrm{xL}$ expression. In addition, we observed that individual primary $\mathrm{E} \mu-M y c$ clones isolated from distinct mice had different levels of endogenous GAPDH that correlated closely with increase in phospho-Akt and Bcl-xL overexpression (Figure $5 b$ ). Indeed clone 516 was the one with the highest endogenous level of GAPDH, phospho-Akt and Bcl-xL levels (Figure 5b).
Importantly, this increase in endogenous $\mathrm{Bcl}-\mathrm{xL}$ expression observed in clone 516 could be reverted upon GAPDH inhibition (Figure $5 c$ ) using an efficient (Figure 5d) but nontoxic dose of KA (Figure $5 \mathrm{e}$ ) or by knocking down endogenous GAPDH (Figures $5 f$ and $g$ ).

We have, therefore, established in three independent cell lines as in primary lymphoma cells that GAPDH overexpression is able to lead to $\mathrm{Bcl}-\mathrm{xL}$ upregulation. We also showed that a spontaneous GAPDH overexpression was closely correlating with an increase in endogenous $\mathrm{Bcl}-\mathrm{xL}$ expression.

GAPDH-dependent increase in Bcl-xL expression is required for protecting cells from CICD. To uncover the role of GAPDH-dependent $\mathrm{Bcl}-\mathrm{xL}$ expression upon $\mathrm{CICD}$ 
a

GAPDH-V5

$\begin{array}{llllllllllll} & 0.5 & 1 & 3 & 5 & 8 & 0 & 0.5 & 1 & 3 & 5 & 8\end{array}$

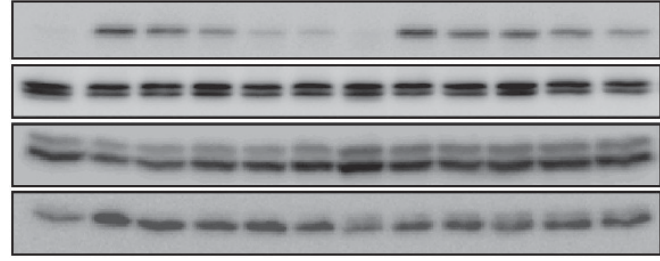

Insulin (Hrs)

pAkt-ser473

Akt

pErk1/2-

thr202/tyr204

Erk2

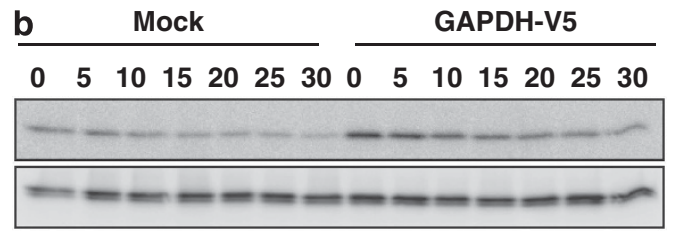

Time at

$30^{\circ} \mathrm{C}$ (min)

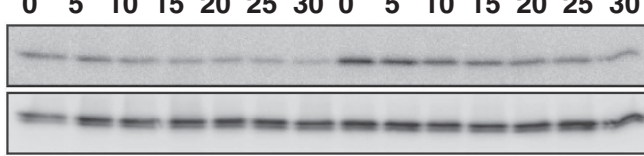

pAkt-ser473

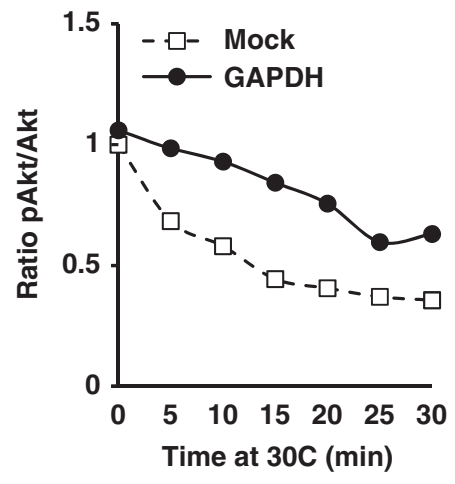

Akt
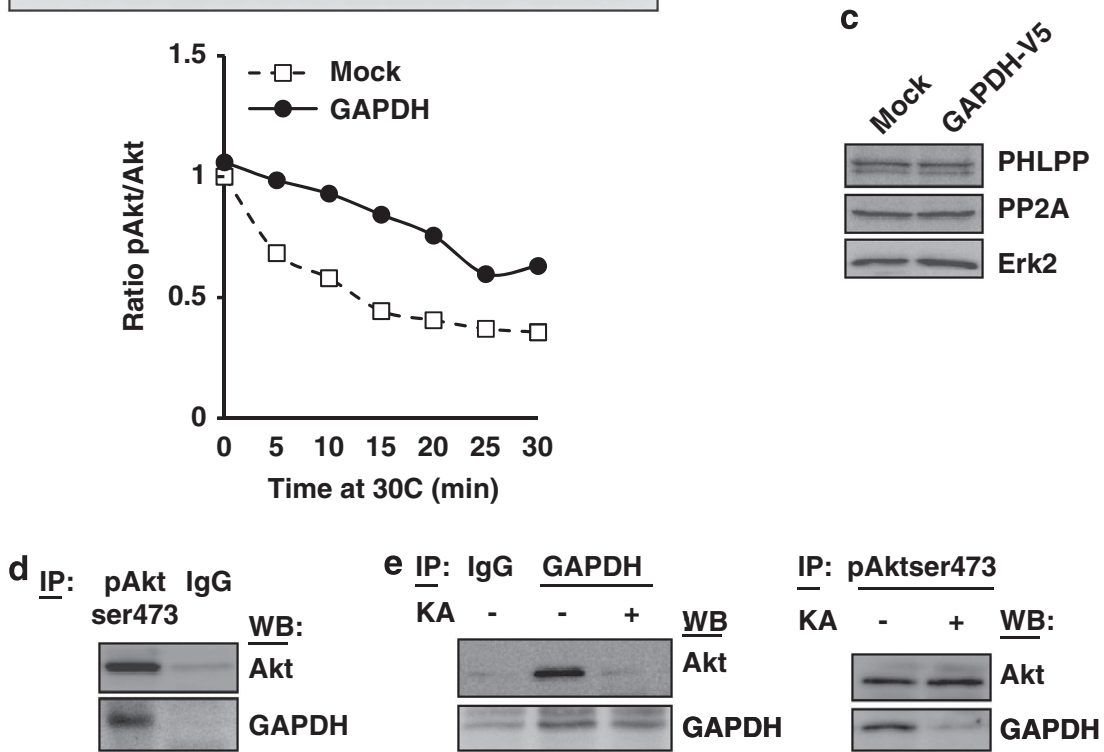

Figure 3 GAPDH limits the dephosphorylation of activated Akt by direct binding. (a) Mock or GAPDH-V5 HeLa cells were deprived of serum for $16 \mathrm{~h}$ and then stimulated with $200 \mathrm{nM}$ insulin for the indicated time periods. Akt and Erk activation was assessed by immunoblots of phospho- or total protein. (b) Mock or GAPDH-V5 HeLa cells were treated with insulin $(200 \mathrm{nM})$ for $30 \mathrm{~min}$ as described in panel a, lysed on ice without phosphatase inhibitors and then incubated at $30^{\circ} \mathrm{C}$ for the indicated time periods. Akt activation was assessed by immunoblot and the pAkt/Akt ratio was quantified, shown in the lower panel, and normalized to time '0' of the Mock cells. (c) Mock or GAPDH-V5 HeLa cells were immunoblotted for the indicated proteins. (d) 293T cells were transiently co-transfected with a GAPDH-V5- and an Akt-encoding vector. After $48 \mathrm{~h}$, the cells were subjected to immunoprecipitation using anti-pAkt $\left(\mathrm{Ser}^{473}\right)$ or an lgG control. Presence of co-immunoprecipitated GAPDH was assessed by western blot. (e) HeLa cells were treated or not with $0.5 \mu \mathrm{g} / \mathrm{ml} \mathrm{KA}$ for $24 \mathrm{~h}$ and subjected to immunoprecipitation using anti-GAPDH (left panel), anti-pAkt (Ser ${ }^{473}$, right panel) or an lgG control. Presence of co-immunoprecipitated Akt and GAPDH was assessed by western blot. IP, immunoprecipitation; WB, western blot. Results are representative of three independent experiments

protection, ABT-737, a BH3-mimetic drug that binds to the anti-apoptotic proteins $\mathrm{Bcl}-2$, Bcl-xL and $\mathrm{Bcl}-\mathrm{w},{ }^{31}$ was used. Although ABT-737 was not toxic over time (Supplementary Figure 5A), it prevented GAPDH-dependent protection from CICD (Figure 6a). In addition, $\mathrm{Bcl}-\mathrm{xL}$ overexpression (Supplementary Figure 5B) induced a significant level of protection of Mock cells from CICD, but did not enhance the protection induced by GAPDH (Figure 6b). These data indicate that GAPDH overexpression increases $\mathrm{BCl}-\mathrm{xL}$ expression, which was required for survival from CICD.

GAPDH-dependent increase in Bcl-xL is mediated by Akt stabilization, which prevents FoxO's ability to induce Bcl-6. To understand how GAPDH could increase $\mathrm{Bcl}-\mathrm{xL}$ levels, $\mathrm{Bcl}-6$ expression was investigated as it is a $\mathrm{Bcl}-\mathrm{xL}$ transcriptional repressor controlled by $\mathrm{Akt}^{32} \mathrm{Bcl}-6$ was expressed at significantly lower levels in GAPDH-expressing cells than in control cells (Figures $7 \mathrm{a}$ and b). In addition, $\mathrm{Bcl}-6$ expression was found to be inversely correlated with the level of GAPDH expression in the primary lymphoma cells (Figure $5 b$ ). Decrease of this transcriptional repressor upon GAPDH overexpression correlated closely with an increase in $\mathrm{Bcl}-\mathrm{xL}$ (Figures 7b and c, and Figure 5b). Importantly, this increase in transcription of $\mathrm{Bcl}-\mathrm{xL}$ could be significantly reversed using the Akti or KA (Figure 7d).

We then decided to determine whether endogenous levels of GAPDH could control Bcl- 6 and $\mathrm{Bcl}-\mathrm{xL}$ expression. We, therefore, knocked down GAPDH in HeLa cells 

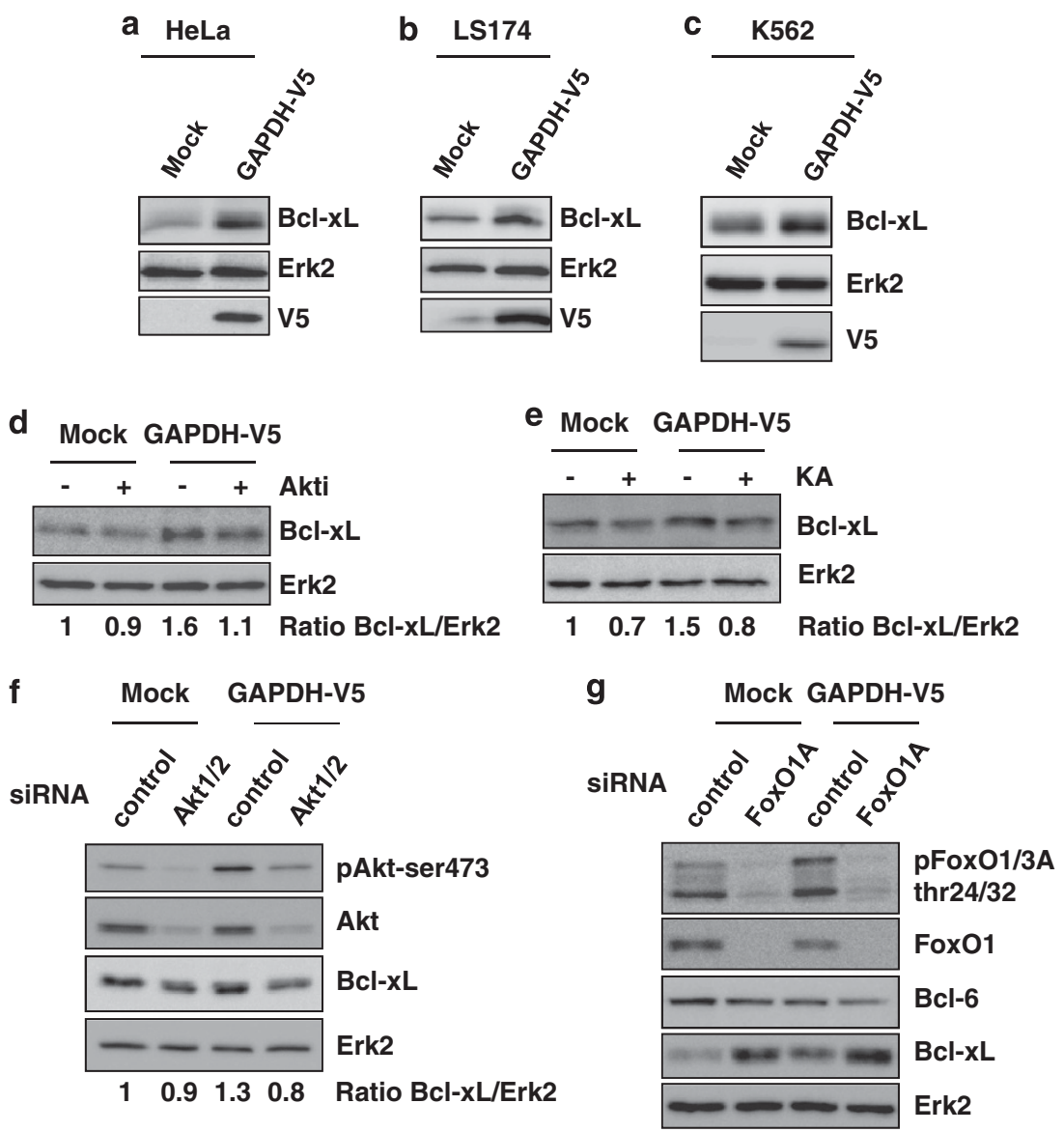

Figure 4 GAPDH overexpression induces Bcl-xL upregulation in several cell lines through Akt pathway activation. (a-c) Expression of Bcl-xL was assessed by immunoblots of Mock and GAPDH-V5-overexpressing HeLa (a), LS174 (b) or K562 (c) cell lines. (d and e) Mock or GAPDH-V5 HeLa cells were treated for $48 \mathrm{~h}$ with $1 \mu \mathrm{M}$ Akti (d) or $0.5 \mu \mathrm{g} / \mathrm{ml} \mathrm{GAPDH}$ inhibitor (KA, e), and analyzed as described in panel a. (f and $\mathbf{g}$ ) Mock or GAPDH-V5 HeLa cells were transiently transfected $48 \mathrm{~h}$ with $50 \mathrm{nM}$ siRNA targeting Akt1/2 (f) or FoxO1A (g), and analyzed as described in panel $\mathbf{a}$. The immunoblots are representative of 3-5 independent experiments. Erk2 was used as a loading control. The Bcl-xL/Erk2 ratios were quantified and normalized to Mock cells

(Figures 7e and f) and observed an increase in Bcl-6 and a decrease in $\mathrm{Bcl}-\mathrm{xL}$ expression, which is in agreement with our described mechanism.

Finally, we knocked down Bcl-6 to further establish the role of its GAPDH-mediated decrease in protection from CICD. We observed that upon Bcl-6 decrease, Bcl-xL expression increased (Figures $7 \mathrm{~g}$ and $\mathrm{h}$ ). Very importantly, we established that the Bcl-6 knockdown was sufficient to allow clonogenic outgrowth upon CICD induction (Figure 7i). Altogether, our results indicate that GAPDH-dependent protection from CICD is linked to stabilization of activated Akt, which leads to $\mathrm{Bcl}-6$ downregulation, resulting in $\mathrm{Bcl}-\mathrm{xL}$ overexpression.

GAPDH-dependent $\mathrm{Bcl}-\mathrm{xL}$ expression is protecting some mitochondria from permeabilization. It was recently suggested that upon cell death not all mitochondria in a cell necessarily undergo MOMP, a process defined as incomplete MOMP (iMOMP). ${ }^{33}$ Interestingly, iMOMP mitochondria seem to be required for clonogenic growth upon stress, as they provide a pool of intact mitochondria that permit cellular recovery following MOMP. ${ }^{33}$ We established that Smac-GFP HeLa cells overexpressing GAPDH have more iMOMP than control cells (Figures $8 a$ and b). Of note, Smac-GFP cells expressing GAPDH or control cells were verified to be killed in a similar way upon a kinetic analysis of apoptosis (i.e., caspase-dependent) induction (not shown). As ABT-737 was able to prevent GAPDH-dependent protection from CICD (Figure 6a), we measured the percentage of cells showing iMOMP in the presence of this $\mathrm{BH} 3$ mimetic. Whereas the GAPDH-expressing cells showed significantly more iMOMP compared with the control cells, this effect was decreased in the presence of ABT-737 (Figure 8b). We then reasoned that if GAPDH-dependent protection from CICD is dependent on Akt activation (Figure 2), leading to $\mathrm{Bcl}-\mathrm{xL}$ overexpression (Figures 4 and 5), then inhibiting Akt or GAPDH should also decrease the number of protected mitochondria. Along this direction, the percentage of iMOMP mitochondria was significantly reduced in the GAPDH Smac-GFP cells in the presence of the Akti or $\mathrm{KA}$ (Figures 8c and d).

Finally, we hypothesized that protection of specific mitochondria in a GAPDH-expressing cell undergoing MOMP upon $\mathrm{CICD}$ was due to an increased level of $\mathrm{Bcl}-\mathrm{xL}$ localized 

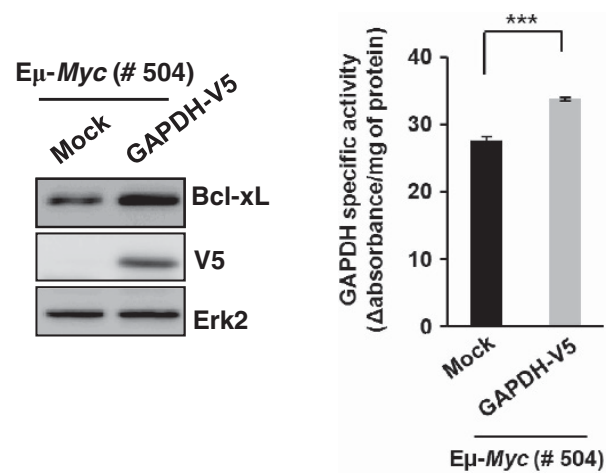

d

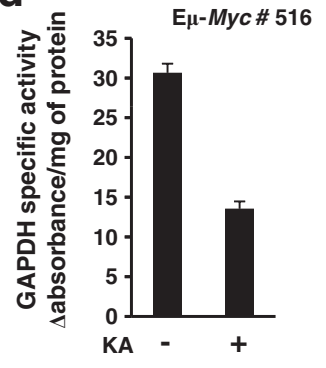

E $\mu-M y c$ lymphoma cells
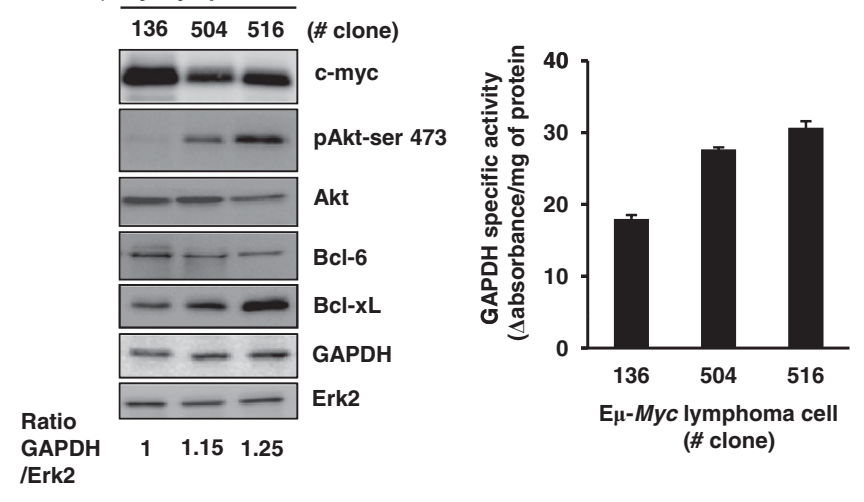

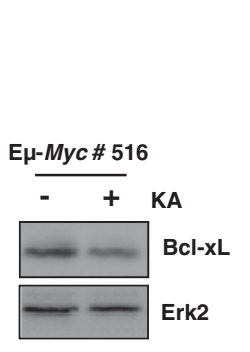

C e

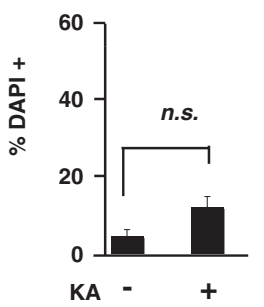

f

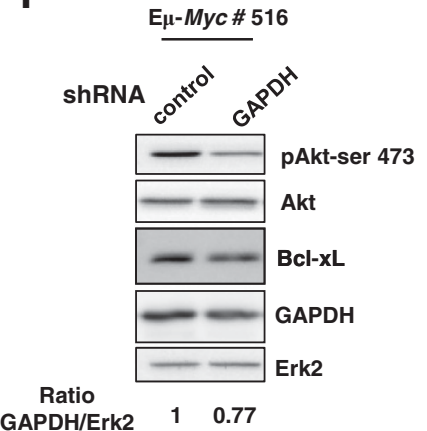

g

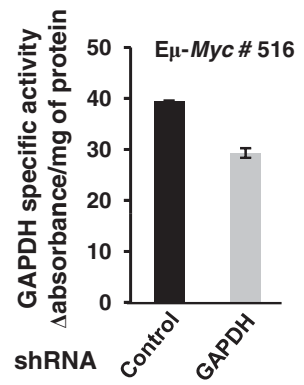

Figure $5 \mathrm{Bcl}-\mathrm{xL}$ expression is upregulated in primary mouse lymphoma cells in a GAPDH-dependent manner. (a) Primary lymphoma cells were isolated from an $\mathrm{E} \mu$-Myc mouse (number \#504) and transduced with a control (Mock) or a GAPDH-V5-encoding vector. GAPDH specific activity (right), and the level of Bcl-xL and V5 expression (left), were analyzed as described previously. (b) Primary lymphoma cells were isolated from three $\mathrm{E} \mu$-Myc mice (\#136, \#504 and \#516) and the level of the indicated proteins was analyzed by immublots. The GAPDH/Erk2 ratio was quantified and normalized to clone \#136. (Right) GAPDH activity was measured in those clones. (c) E $\mu$-Myc lymphoma cells (\#516) were treated for $48 \mathrm{~h}$ with $0.25 \mu \mathrm{g} / \mathrm{ml} \mathrm{KA}$ and analyzed as described in panel a. Specific GAPDH activity (d) and cytotoxicity of the treatment (e, analyzed by FACS) were measured under the same conditions. (f and $\mathbf{g}$ ) Protein expression (f) and GAPDH activity (g) were assessed in E $\mu$-Myc lymphoma cells (\#516) transduced with either a control or an shRNA vector targeting GAPDH. The GAPDH/Erk2 ratio was quantified and normalized to control cells. The data shown are the means of three independent experiments and expressed as means \pm S.D. ${ }^{* \star *} P<0.005$. n.s., not significant

on this specific intact organelle. Therefore, GAPDH-SmacGFP cells were treated with actinomycin-D (Act-D) in the presence of $\mathrm{Q}-\mathrm{VD}-\mathrm{OPh}$ and imaged $24 \mathrm{~h}$ later. In cells showing iMOMP (Figure 8e), increased levels of endogenous $\mathrm{Bcl}-\mathrm{xL}$ were observed on non-permeabilized mitochondria, suggesting it was responsible for protecting the intact mitochondria from MOMP. It is important to note that all those observations could be reproduced when CICD was induced using another death stimulus (Supplementary Figures 6A and B).

\section{Discussion}

The rapid loss of mitochondrial function during apoptosis is not dependent on MOMP per se, but rather on the subsequent activation of caspases. ${ }^{34-36}$ However, even upon caspase inhibition, MOMP will eventually lead to 'caspase-independent cell death'. Because cancer cells have to develop ways to prevent all forms of cell death to survive oncogenic transformation or resist chemotherapy, understanding the underlying escape mechanisms seems important. So far, the vast majority of studies have been centered on the identification of escape mechanisms of cancer cells from apoptosis. This led to the discovery that several types of human tumors have diverse ways to prevent apoptosis. ${ }^{6}$ However, many studies showed that a complete caspase inhibition is often not sufficient to allow oncogenic transformation or survival from chemotherapy as CICD will prevent it. ${ }^{17,37}$ Therefore, uncovering CICD's molecular mechanism seems essential. We recently established that increased GAPDH expression could allow cells to recover from MOMP and be protected from CICD. ${ }^{17}$ This protective effect of GAPDH was dependent on its glycolytic function and ability to induce the mitophagy of damaged mitochondria. However, as intact mitochondria are required to generate the new and functional organelles needed for cell recovery and proliferation, understanding how some mitochondria can be protected by GAPDH during CICD remained to be found.

Here, we show that GAPDH overexpression stabilized activated Akt (Figure 1). This stabilization was dependent on the ability of GAPDH to bind to phospho-Akt (either directly or through a complex of proteins; Figure 3), which was in turn 
a

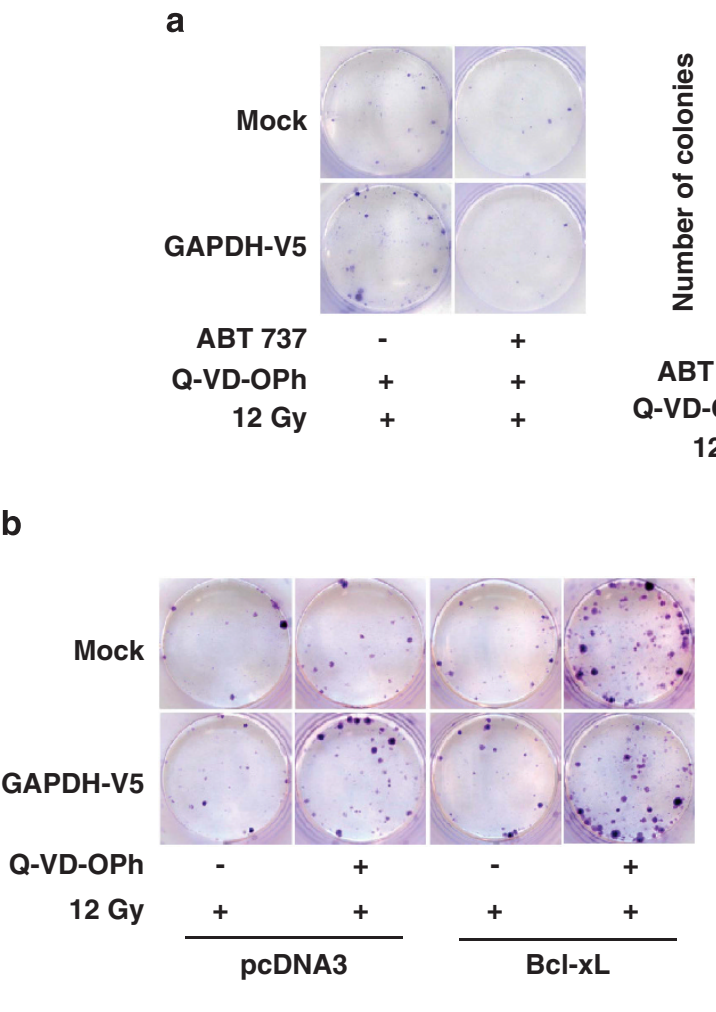

b

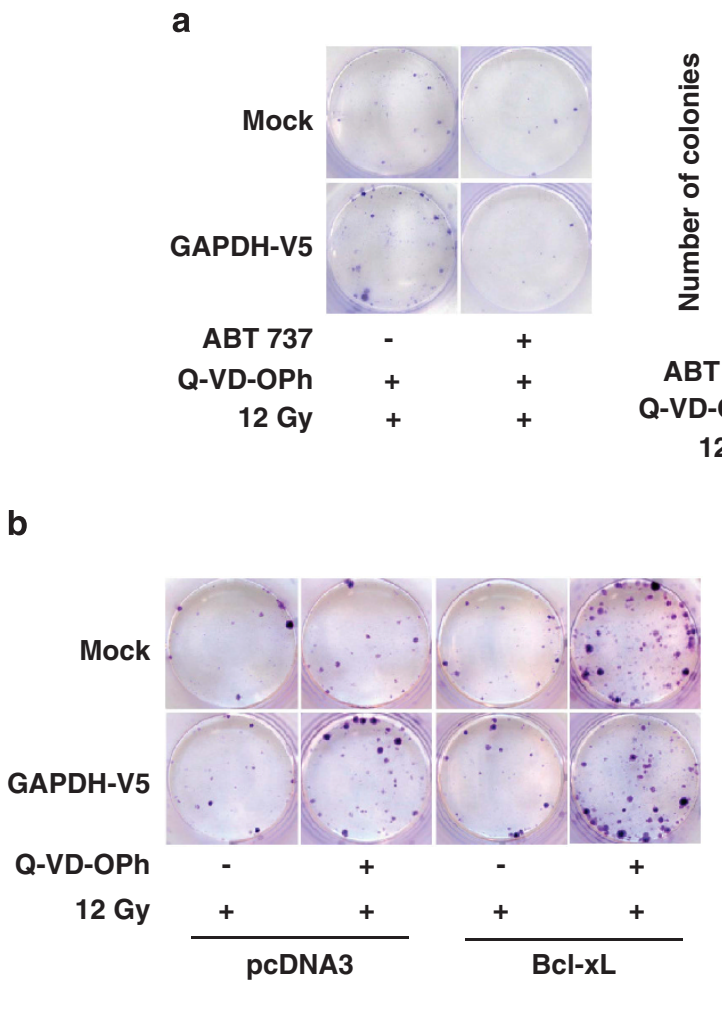

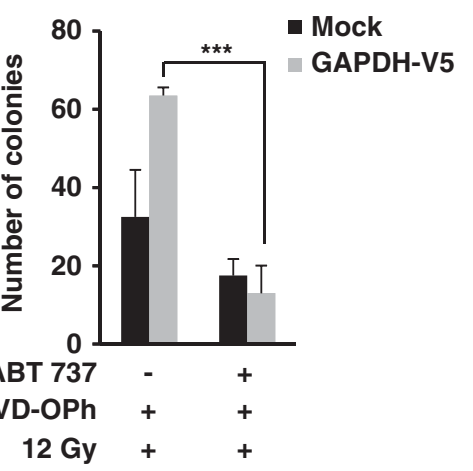

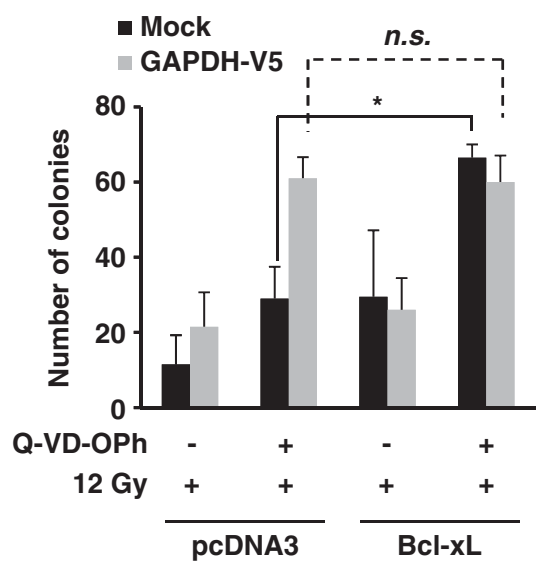

Figure 6 Bcl-xL upregulation is required for GAPDH-dependent protection from CICD. (a) Mock and GAPDH-V5-overexpressing HeLa cells were treated with or without ABT-737 $(10 \mu \mathrm{M})+\mathrm{Q}-\mathrm{VD}-\mathrm{OPh}(20 \mu \mathrm{M})$. Inhibitors were added 30 min before a 12-Gy irradiation step and replaced periodically at 48 -h intervals for 10 days. Colonies were stained and quantified as described in Figure 1d. (b) Mock or GAPDH-V5-expressing cells were transiently transfected with a control vector $\left(\mathrm{pcDNA}_{3}\right)$ or a vector encoding Bcl$\mathrm{xL}$. After $48 \mathrm{~h}$, the cells were treated with or without $20 \mu \mathrm{M}$ Q-VD-OPh, and then irradiated (12 Gy). Colonies were stained 18 days later. The quantifications are the means of $3-5$ independent experiments. ${ }^{* * *} P<0.005,{ }^{*} P<0.05$. n.s., not significant

dependent on GAPDH activity as its inhibition using the covalent inhibitor, KA, prevents its binding with phospho-Akt (Figure $3 e$ ) and stabilization of active Akt in cells (Figure 1e). We also observed no modification of Akt phosphatases in the GAPDH-expressing cells (Figure 3c). Altogether, our data suggest that once produced, binding of phospho-Akt to GAPDH limits the action of endogenous phosphatases (which remains to be found), thereby maintaining its activity over time (Figure 3). In this direction, recent reports indicate that GAPDH can modulate the PI3K pathway ${ }^{38}$ and that GAPDH has the ability to interact with Akt in other settings. ${ }^{39,40}$ Therefore, once stabilized by GAPDH, activated Akt leads to FoxO phosphorylation (Figure 1a), preventing its nuclear relocalization and resulting in $\mathrm{Bcl}-6$ downregulation (Figures 7a and b). Decrease of this transcriptional inhibitor leads to enhancement of $\mathrm{Bcl}-\mathrm{xL}$ expression (Figures 7a, b, c, g and h) and clonogenic outgrowth from CICD (Figure 7i). We also showed that this $\mathrm{GAPDH}$-dependent increase in $\mathrm{Bcl}-\mathrm{xL}$ was required for protection of a subset of mitochondria needed for CICD survival (Figure 8 and Supplementary Figure 6A; the general model is shown in Supplementary Figure 7 ). The results described here that upon GAPDH, but not PGK or enolase, overexpression active Akt is stabilized, leading to $\mathrm{Bcl}-\mathrm{xL}$ expression, represent a new finding linking the expression of a glycolytic enzyme, observed to be overexpressed in human tumors, ${ }^{20}$ to the expression of an anti-apoptotic member.

In agreement with our previous study, ${ }^{17}$ we observed that the GAPDH-dependent $\mathrm{Bcl}-\mathrm{xL}$ overexpression was not able to protect cells from apoptosis, but could efficiently protect them from CICD (Figure 1d). This effect is likely due to the mild overexpression of $\mathrm{Bcl}-\mathrm{xL}$ observed in those cells, which is not able to protect all mitochondria from MOMP (Supplementary Figure 7). Therefore, in the absence of caspase inhibition, the non-protected mitochondria will be permeabilized, leading to apoptosome formation, and executioner caspases will dismantle the cells very quickly before any rescue mechanism can take place. However, upon caspase inhibition, which is observed in several types of cancer, ${ }^{14}$ expressing more Bcl$\mathrm{xL}$ will protect some mitochondria from MOMP and promote the ability of cancer cells to recover from CICD. In addition, CICD is a slow but efficient process for killing a cell. Typically, GAPDH-dependent protection from CICD takes several days following MOMP, which is consistent with the notion that the few protected mitochondria observed in the cells need time to be expended and to generate new organelles in the surviving cells to allow their proliferation. It is important to note that generation of iMOMP mitochondria is not sufficient on its own to protect cells from $\mathrm{CICD}$. It also requires other repair 


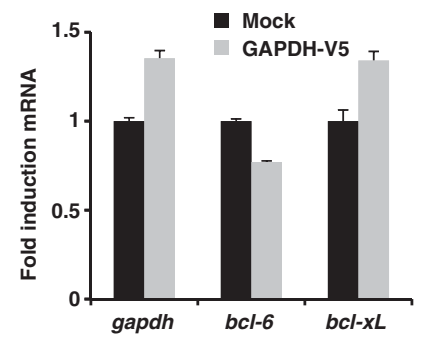

b

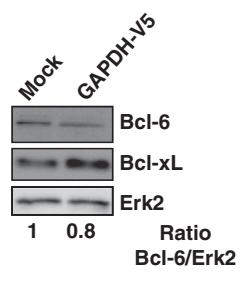

c

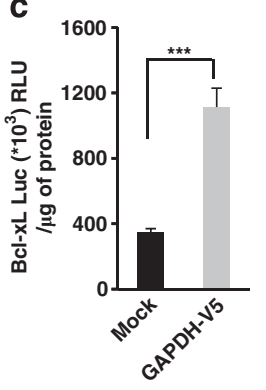

e

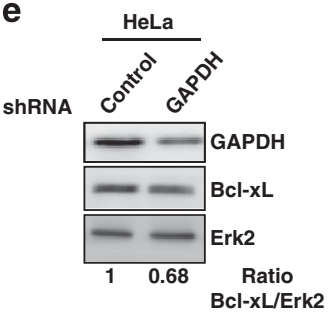

d $\quad \overbrace{* * *}^{* * *}$
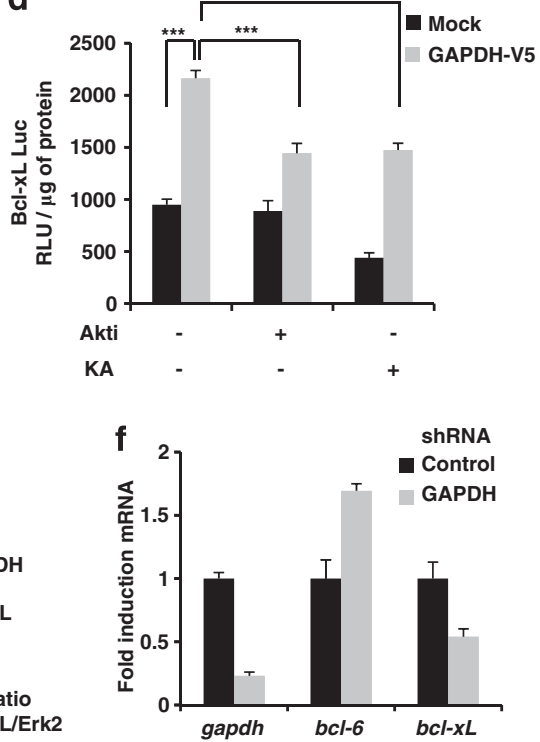
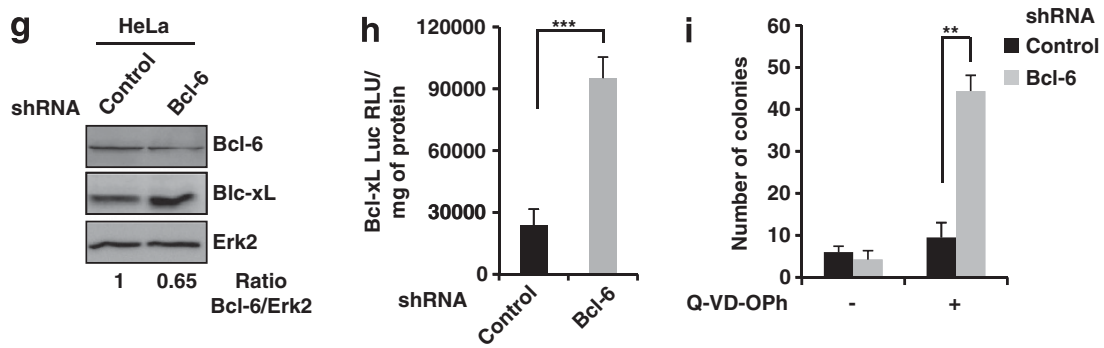

Figure 7 GAPDH-dependent stabilization of active Akt leads to an increase in Bcl-xL expression via a decrease of Bcl-6. (a) Total mRNA was extracted from Mock and GAPDH-V5-overexpressing HeLa cells, and assessed by real-time RT-PCR for GAPDH, Bcl-6 and Bcl-xL expression. Relative mRNA values were determined, normalized to $18 \mathrm{~S}$ and reported in terms of folds of the control. (b) As in panel a for assessing Bcl-6 and Bcl-xL protein level. The Bcl-6/Erk2 ratio was quantified and normalized to Mock cells. (c) Mock or GAPDH-overexpressing HeLa cells were transiently co-transfected with a Bcl-xL promoter-luciferase construct and a GFP-encoding vector. After $48 \mathrm{~h}$, transfection efficiency and luciferase activity were assessed for each condition. (d) Cells were treated with or without $1 \mu \mathrm{M}$ Akti or $0.5 \mu \mathrm{g} / \mathrm{ml}$ GAPDH inhibitor (KA) for $48 \mathrm{~h}$ and analyzed as described in panel c. (e and f) Proteins (e) or total mRNA (f) were extracted from HeLa cells transduced with either a control or an shRNA vector targeting GAPDH. GAPDH, Bcl-6 and Bcl-xL levels were assessed by western blot (e) or real-time RT-PCR (f). Relative mRNA values were determined, normalized to $18 \mathrm{~S}$ and reported in terms of folds of the control. (g) Bcl-6 and Bcl-xL protein levels were assessed in HeLa cells transduced with either a control or an shRNA vector targeting Bcl-6. The Bcl-6/Erk2 ratio was quantified and normalized to Mock cells. (h) HeLa cells transduced with a control or a Bcl-6 shRNA vector were analyzed as described in panel c. (i) HeLa cells transduced as shown in $\mathbf{h}$ were analyzed as described in Figure 1d. Erk2 was used as a loading control. The data are the means of three independent experiments. ${ }^{* * *} P<0.005$, ${ }^{* *} P<0.01$, RLU, Relative Luciferase Unit

mechanisms, ${ }^{17}$ coordinated by GAPDH but not by overexpression of PGK or enolase.

The potential clinical relevance of our work relies on the fact that, similarly to most glycolytic enzymes, GAPDH is overexpressed in the vast majority of human tumors in response to oncogenes and/or HIF-1 $\alpha$ stabilization. ${ }^{20}$ As far as we know, however, GAPDH is the only glycolytic protein described so far that is able to lead to an overexpression of $\mathrm{Bcl}-\mathrm{xL}$ and to protect cells specifically from CICD. This protection is dependent on its ability to promote iMOMP, which very likely facilitates cell survival and impacts therapeutic efficacy. In light of these results, the ability of ABT-737 to prevent iMOMP and CICD survival could also contribute to the potency of such chemotherapy. 


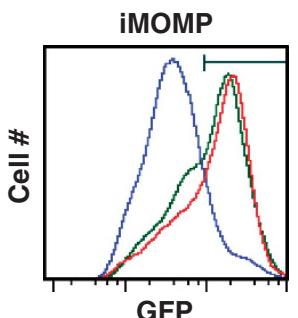

GFP

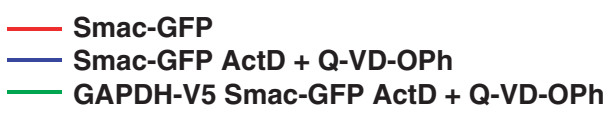

C

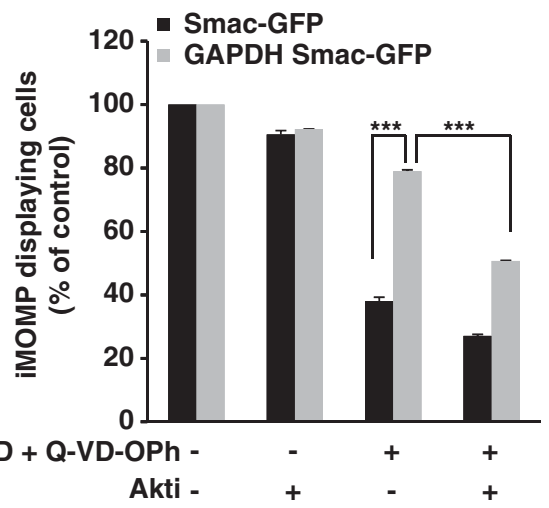

e

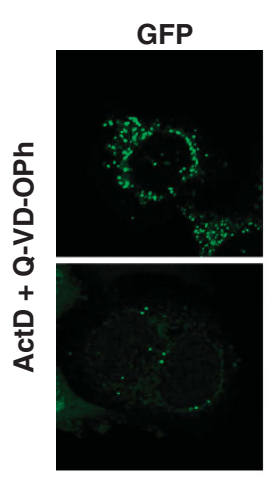

GAPDH Smac-GFP b

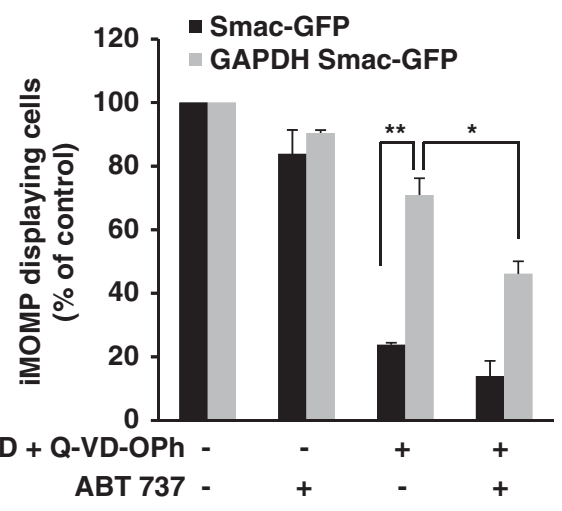

d
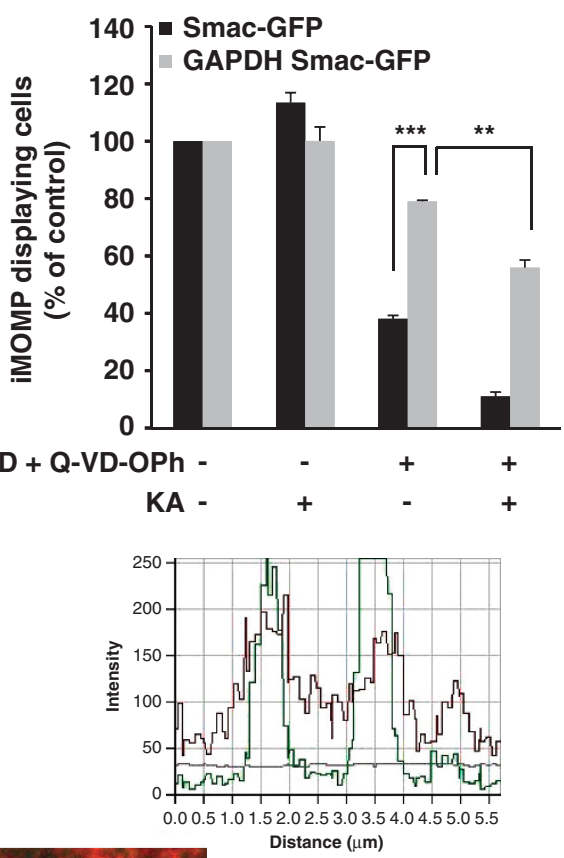

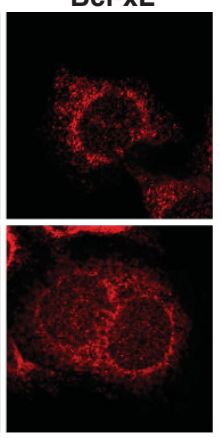

Merged

Figure 8 GAPDH leads to iMOMP through Akt activation and Bcl-xL overexpression. (a) HeLa cells expressing Smac-GFP with or without GAPDH-V5 (as indicated) were treated for $6 \mathrm{~h}$ with Act-D $(0.5 \mu \mathrm{M})+\mathrm{Q}-\mathrm{VD}-\mathrm{OPh}(20 \mu \mathrm{M})$ and analyzed by flow cytometry for GFP fluorescence intensity $72 \mathrm{~h}$ later. The gate denotes the population with the highest number of Smac-GFP-fluorescent cells. (b-d) The indicated HeLa cells were treated for $6 \mathrm{~h}$ with Act-D $(0.5 \mu \mathrm{M})+\mathrm{Q}-\mathrm{VD}-\mathrm{OPh}(20 \mu \mathrm{M})$ in the presence of $10 \mu \mathrm{M}$ ABT737 (b), $1 \mu \mathrm{M}$ Akti (c) or $0.5 \mu \mathrm{g} / \mathrm{ml} \mathrm{KA}$ (d). After $72 \mathrm{~h}$, the cells were analyzed by flow cytometry for GFP fluorescence intensity. iMOMP-displaying cells are represented as the population with the highest Smac-GFP fluorescence (as \% of control untreated cells). (e) A representative confocal microscopy image from single-cell cultures showing intact cells (top) and iMOMP (bottom) in HeLa cells expressing GAPDH and Smac-GFP. The cells were treated with $0.5 \mu \mathrm{M}$ Act-D and the caspase inhibitor Q-VD-OPh (20 $\mu \mathrm{M}$ ) for $6 \mathrm{~h}$. The caspase inhibitor was added $30 \mathrm{~min}$ before the apoptotic agent. After $24 \mathrm{~h}, \mathrm{MOMP}$ and Bcl-xL expression was analyzed by confocal microscopy. The line scan (right) indicates colocalization of Smac-GFP and Bcl-xL, and correlates with the line drawn in the image. The data are the means of three independent experiments. ${ }^{* \star *} P<0.005$, ${ }^{*} P<0.01,{ }^{*} P<0.05$. The confocal images are representative of five independent experiments

\section{Materials and Methods}

Reagents and antibodies. Anti-Erk2 was purchased from Santa Cruz Biotechnology (Santa Cruz, CA, USA). Anti-V5 was purchased from Invitrogen (Carlsbad, CA, USA). Other antibodies were purchased from Cell Signaling Technology (Beverly, MA, USA). KA was a kind gift from Dr. Keiji Hasumi (Tokyo Noko University). ABT-737 was a generous gift from Abbott Laboratories (Abbott Park, IL, USA). Act-D, staurosporine, Akti and insulin were purchased from Sigma (St. Louis, MO, USA), and Q-VD-OPh was purchased from SM Biochemicals (Yorba Linda, CA, USA).
Cell culture. Human cervical cancer HeLa cells, human colon adenocarcinoma LS174 cells and human embryonic kidney 293T cells were cultured in DMEM supplemented with $10 \%$ fetal calf serum and $100 \mathrm{U} / \mathrm{ml}$ of penicillin and streptoMycin. Chronic myeloid leukemic K562 cells were cultured in RPMI medium supplemented with $5 \%$ fetal calf serum. E $\mu$-Myc lymphoma cells (B lymphoma cells) were isolated as described previously ${ }^{41}$ and cultured in DMEM supplemented with $10 \%$ fetal calf serum, 2-mercaptoethanol $(50 \mu \mathrm{M})$, L-asparagin $(0.37 \mathrm{mM})$ and HEPES $(\mathrm{pH} 7.4,1 \mathrm{mM})$. GAPDH-overexpressing cells were infected as described previously. ${ }^{17} \mathrm{HeLa}$ and $293 \mathrm{~T}$ cells were 
transiently transfected by the calcium phosphate method using the indicated vectors. $^{42}$

Proliferation assays. Cells $\left(6 \times 10^{4}\right)$ were seeded in $35-\mathrm{mm}$ dish. The cells were detached $24 \mathrm{~h}$ after seeding and counted every $24 \mathrm{~h}$ for 4 days. The proliferation index was calculated by dividing the cell number obtained for each day by that obtained $24 \mathrm{~h}$ after seeding.

Cell death and iMOMP assays. After treatment, cells were resuspended in $200 \mu$ of phosphate-buffered saline (PBS) containing $0.5 \mathrm{mg} / \mathrm{ml} 4^{\prime}$,6-diamidino2-phenylindole (DAPI), and the samples were analyzed immediately by flow cytometry using a MACSQuant analyzer (Miltenyi Biotec, Bergisch Gladbach, Germany), the percentage of dying cells corresponding to the percentage of DAPIpositive cells. HeLa cells expressing Smac-GFP and GAPDH were analyzed for iMOMP by measuring the highest GFP-fluorescent populations as described by Tait et al. ${ }^{33}$

Clonogenicity assays. HeLa cells $\left(6 \times 10^{3}\right)$ were seeded in a 12-well plate. The next day, the cells were pretreated with or without Q-VD-OPh $(20 \mu \mathrm{M})$ and/or the indicated product for 30 min and then irradiated with 12 Gy using an X-ray irradiator RS 2000 (RAD Source, Suwanee, GA, USA). If added, Q-VD-OPh was replaced periodically at $48-\mathrm{h}$ intervals for 10 days. The colonies were stained for 20 min with crystal violet ( $0.4 \%$ crystal violet, $20 \% \mathrm{EtOH})$ and assessed 18 days after treatment.

Measurement of GAPDH activity. Cells were lysed in buffer containing $10 \mathrm{mmol} / \mathrm{l}$ HEPES (pH 7.4), $150 \mathrm{mmol} / \mathrm{l} \mathrm{NaCl}, 5 \mathrm{mmol} / \mathrm{l}$ EDTA, $1 \% \mathrm{NP}-40,10 \mu \mathrm{g} / \mathrm{ml}$ aprotinin, $1 \mathrm{mmol} / /$ phenylmethylsulfonyl fluoride (PMSF) and $10 \mu \mathrm{mol} / \mathrm{l}$ leupeptin. Lysates were standardized for protein content and incubated with $0.25 \mathrm{mmol} / \mathrm{l}$ $\mathrm{NAD}, 3.3 \mathrm{mmol} / \mathrm{I} \mathrm{DTT}, 13 \mathrm{mmol} / \mathrm{l} \mathrm{Na} \mathrm{N}_{4} \mathrm{P}_{2} \mathrm{O}_{7}(\mathrm{pH} 8.5), 26 \mathrm{mmol} / /$ sodium arsenate and $25 \mathrm{mmol} / \mathrm{l}$ D-glyceraldehyde-3-phosphate in a black 96-well plate (Cellstar). GAPDH activity was measured on a fluoroscan at $445 \mathrm{~nm}$ as increase in fluorescence related to $\mathrm{NADH}$ accumulation. Activity is expressed as change in absorbance per milligram of protein.

Western blot analysis. After treatment, cells were collected, washed in PBS and lysed as described previously. ${ }^{21}$ When indicated, western blot quantification was performed using the multigauge software (Fujifilm).

Plasmids and interfering RNAs. GAPDH (M33197), PGK (NP_000282.1) and enolase (NP_001419) were cloned by PCR into a pcDNA3.1/V5-His TOPO TA expression plasmid (Invitrogen) using a cDNA library and following classical methods. GAPDH was then subcloned into a pMIG viral vector for retroviral infection. Control or human GAPDH-targeting shRNA ${ }^{21}$ were cloned into a pSUPER retro.Neo + GFP (oligoengine). The shRNA targeting GAPDH in mouse cells was obtained using the oligonucleotide sequences forward $5^{\prime}$-GATCCCCC TACATGGTCTACATGTTCTTCAAGAGAGAACATGTAGACCATGTAGTTTTTA-3' and reverse $5^{\prime}$-AGCTTAAAAACTACATGGTCTACATGTTCTCTCTTGAAGAACA TGTAGACCATGTAGGGG-3', and inserted into the pSUPER retro.Neo + GFP.

siRNAs targeting Akt1/2 (sc-43609; Santa Cruz Biotechnology) and FoxO1 (Thermoscientific Dharmacon, Lafayette, CO, USA) were transiently transfected into HeLa cells using RNAiMax (Invitrogen) at $50 \mathrm{nM}$ for $48 \mathrm{~h}$. Stable downregulation of Bcl-6 was obtained using a pLKO.1-Puro vector shRNA lentiviral transduction using the sequence TRCN0000135663 (Sigma) and selection with puromycin $(10 \mu \mathrm{g} / \mathrm{ml}$; Invivogen, San Diego, CA, USA).

Co-immunoprecipitation. Protein-G-Sepharose 4B beads (Invitrogen) were first incubated with an anti-phospho-Akt, anti-GAPDH antibody or a rabbit IgG control (Santa Cruz Biotechnology) for $3 \mathrm{~h}$ at $4{ }^{\circ} \mathrm{C}$. The beads were then incubated for $6 \mathrm{~h}$ with $2 \mathrm{mg}$ of protein lysed in $40 \mathrm{mM}$ Tris- $\mathrm{HCl}(\mathrm{pH} 7.4), 150 \mathrm{mM}$ $\mathrm{NaCl}, 20 \mathrm{mM}$ EDTA, $50 \mathrm{mM} \mathrm{NaF}, 0.2 \%$ NP-40, $0.1 \mathrm{mM} \mathrm{Na} \mathrm{VO}_{4}, 20 \mu \mathrm{g} / \mathrm{ml}$ leupeptin, $20 \mu \mathrm{g} / \mathrm{ml}$ aprotinin and $1 \mathrm{mM}$ PMSF obtained from 293T cells $48 \mathrm{~h}$ after transfection or HeLa cells. The samples were then washed five times with lysis buffer, boiled in Laemmli buffer and analyzed by western blot.

Real-time PCR. Total RNA was extracted from HeLa cells using the Trizol reagent (Life Technologies, Gaithersburg, MD, USA) according to the manufacturer's instructions. Briefly, cultured cells were homogenized in $1 \mathrm{ml}$ Trizol and centrifuged after addition of chloroform. RNA was precipitated with isopropanol and washed with $75 \%$ ethanol. RNA purity was evaluated by spectrophotometry. Total RNA $(2 \mu \mathrm{g})$ was added to a $20-\mu$ l reverse transcriptionPCR (RT-PCR) reaction using the Omniscript kit (Qiagen Inc., Valencia, CA, USA). The relative expression levels of GAPDH, Bcl- 6 and $\mathrm{Bcl}-\mathrm{xL}$ were quantified by realtime RT-PCR using the TaqMan PCR Master Mix (Eurogentec, Seraing, Belgium) and a TaqMan assay primer set (Applied Biosystems, Foster City, CA, USA) using the 7500 Fast (Applied Biosystems) according to the manufacturer's instructions (sequences provided upon request). The relative amounts of $\mathrm{GAPDH}, \mathrm{Bcl}-6$ and $\mathrm{Bcl}-\mathrm{xL}$ were compared with an $18 \mathrm{~S}$ internal control and fold stimulation was calculated.

Luciferase assay. After co-transfection with a Bcl-xL promoter-luciferase construct $^{43}$ and a control GFP-expressing vector, cells were lysed in a reporter lysis buffer (Promega, Madison, WI, USA) for $15 \mathrm{~min}$ and the lysate was cleared by centrifugation. The luciferase assay was performed using the luciferase assay reagent (Promega) according to the manufacturer's instructions and the results were quantified with a centro LB 960 luminometer (Berthold Technologies, Bad Wildbad, Germany). Luciferase activity was normalized to the transfection efficiency and protein amount under each condition.

Immunofluorescence and microscopy. HeLa cells (expressing SmacGFP and overexpressing GAPDH or not) were grown on glass coverslips and fixed with $3 \%$ paraformaldehyde for 20 min followed by incubation for $1 \mathrm{~h}$ in a solution (BSA $1 \%$, saponin $0.2 \%$ ) containing a Bcl-xL antibody, followed by incubation for $1 \mathrm{~h}$ with an anti-rabbit Alexa 594-conjugated IgG antibody (Molecular Probes, Invitrogen). The cells were mounted on slides and analyzed with an LSM 510 confocal microscope (Zeiss, Oberkochen, Germany).

Statistical analysis. Statistics were performed using two-tailed Student's $t$-test. All values shown in the text and figures are \pm S.D.

\section{Conflict of Interest}

The authors declare no conflict of interest.

Acknowledgements. We thank Drs. Tait and Green (St. Jude Hospital, Memphis); Imbert, Peyron, Bost and Luciano (Inserm, U1065); Mari (UMR 6097); Hasumi (Tokyo Noko University); and Munoz-Pinedo (IDIBELL) for reagents, insights and discussions. This work was supported in part by the 'Association pour la Recherche sur le Cancer' (ARC), la 'Fondation de France' and 'l'Agence Nationale de la Recherche' (ANR-09-JCJC-0003). M.A.J. received a fellowship from la Région PACA, Vincience and 'Fondation pour la Recherche Médicale' (FRM). A.C. and J.C. were supported by ARC. M.B. was supported by FRM. O.M. was supported by ANR. J.E.R. and M.C. were recipients of a contrat d'interface INSERM-CHU de Nice.

1. Hanahan D, Weinberg RA. Hallmarks of cancer: the next generation. Cell 2011; 144 : 646-674.

2. Munoz-Pinedo C, El Mijyad N, Ricci JE. Cancer metabolism: current perspectives and future directions. Cell Death Dis 2012; 3: e248.

3. Vander Heiden MG, Cantley LC, Thompson CB. Understanding the Warburg effect: the metabolic requirements of cell proliferation. Science 2009; 324: 1029-1033.

4. Hotchkiss RS, Strasser A, McDunn JE, Swanson PE. Cell death. N Engl J Med 2009; 361 : 1570-1583.

5. Llambi F, Moldoveanu T, Tait SW, Bouchier-Hayes L, Temirov J, McCormick LL et al. A unified model of mammalian BCL-2 protein family interactions at the mitochondria. Mol Cell 2011; 44: 517-531.

6. Pradelli LA, Beneteau M, Ricci JE. Mitochondrial control of caspase-dependent and -independent cell death. Cell Mol Life Sci 2010; 67: 1589-1597.

7. Green DR. Apoptotic pathways: paper wraps stone blunts scissors. Cell 2000; 102: 1-4.

8. McCarthy NJ, Whyte MK, Gilbert CS, Evan GI. Inhibition of Ced-3/ICE-related proteases does not prevent cell death induced by oncogenes, DNA damage, or the Bcl-2 homologue Bak. J Cell Biol 1997; 136: 215-227.

9. Amarante-Mendes GP, Naekyung Kim C, Liu L, Huang Y, Perkins CL, Green DR et al. Bcr$\mathrm{Abl}$ exerts its antiapoptotic effect against diverse apoptotic stimuli through blockage of mitochondrial release of cytochrome $c$ and activation of caspase-3. Blood 1998; 91: 17001705

10. Chautan M, Chazal G, Cecconi F, Gruss P, Golstein P. Interdigital cell death can occur through a necrotic and caspase- independent pathway. Curr Biol 1999; 9: 967-970. 
11. Haraguchi M, Torii S, Matsuzawa S, Xie Z, Kitada S, Krajewski S et al. Apoptotic protease activating factor 1 (Apaf-1)-independent cell death suppression by Bcl-2. J Exp Med 2000; 191: $1709-1720$

12. Xiang J, Chao DT, Korsmeyer SJ. BAX-induced cell death may not require interleukin 1 beta-converting enzyme-like proteases. Proc Natl Acad Sci USA 1996; 93 : $14559-14563$.

13. Lindsten T, Ross AJ, King A, Zong WX, Rathmell JC, Shiels HA et al. The combined functions of proapoptotic Bcl-2 family members bak and bax are essential for normal development of multiple tissues. Mol Cell 2000; 6: 1389-1399.

14. Tait SW, Green DR. Caspase-independent cell death: leaving the set without the final cut. Oncogene 2008; 27: 6452-6461.

15. Deshmukh M, Kuida K, Johnson EM Jr. Caspase inhibition extends the commitment to neuronal death beyond cytochrome $c$ release to the point of mitochondrial depolarization. J Cell Biol 2000; 150: 131-143.

16. Martinou I, Desagher S, Eskes R, Antonsson B, Andre E, Fakan S et al. The release of cytochrome $c$ from mitochondria during apoptosis of NGF-deprived sympathetic neurons is a reversible event. J Cell Biol 1999; 144: 883-889.

17. Colell A, Ricci JE, Tait S, Milasta S, Maurer U, Bouchier-Hayes L et al. GAPDH and autophagy preserve survival after apoptotic cytochrome $c$ release in the absence of caspase activation. Cell 2007; 129: 983-997.

18. Colell A, Green DR, Ricci JE. Novel roles for GAPDH in cell death and carcinogenesis. Cell Death Differ 2009; 16: 1573-1581.

19. Sirover MA. New nuclear functions of the glycolytic protein, glyceraldehyde-3-phosphate dehydrogenase, in mammalian cells. J Cell Biochem 2005; 95: 45-52.

20. Altenberg B, Greulich KO. Genes of glycolysis are ubiquitously overexpressed in 24 cancer classes. Genomics 2004; 84: 1014-1020.

21. Lavallard VJ, Pradelli LA, Paul A, Beneteau M, Jacquel A, Auberger P et al. Modulation of caspase-independent cell death leads to resensitization of imatinib mesylate-resistant cells. Cancer Res 2009; 69: 3013-3020.

22. Cairns RA, Harris IS, Mak TW. Regulation of cancer cell metabolism. Nat Rev Cancer 2011; 11: 85-95.

23. Zhang X, Tang N, Hadden TJ, Rishi AK. Akt, FoxO and regulation of apoptosis. Biochim Biophys Acta 2011; 1813: 1978-1986.

24. Elstrom RL, Bauer DE, Buzzai M, Karnauskas R, Harris MH, Plas DR et al. Akt stimulates aerobic glycolysis in cancer cells. Cancer Res 2004; 64: 3892-3899.

25. Endo A, Hasumi K, Sakai K, Kanbe T. Specific inhibition of glyceraldehyde-3-phosphate dehydrogenase by koningic acid (heptelidic acid). J Antibiot 1985; 38: 920-925.

26. Kumagai S, Narasaki R, Hasumi K. Glucose-dependent active ATP depletion by koningic acid kills high-glycolytic cells. Biochem Biophys Res Commun 2008; 365 362-368.

27. Gao T, Furnari F, Newton AC. PHLPP: a phosphatase that directly dephosphorylates Akt, promotes apoptosis, and suppresses tumor growth. Mol Cell 2005; 18: 13-24.

28. Kuo YC, Huang KY, Yang CH, Yang YS, Lee WY, Chiang CW. Regulation of phosphorylation of Thr-308 of Akt, cell proliferation, and survival by the B55alpha regulatory subunit targeting of the protein phosphatase $2 \mathrm{~A}$ holoenzyme to Akt. J Biol Chem 2008; 283: 1882-1892.

29. Adams JM, Harris AW, Pinkert CA, Corcoran LM, Alexander WS, Cory S et al. The c-myc oncogene driven by immunoglobulin enhancers induces lymphoid malignancy in transgenic mice. Nature 1985; 318: 533-538.

30. Meynet O, Beneteau M, Jacquin MA, Pradelli LA, Cornille A, Carles M et al. Glycolysis inhibition targets $\mathrm{Mcl}-1$ to restore sensitivity of lymphoma cells to ABT-737-induced apoptosis. Leukemia 2012; 26: 1145-1147.

31. Oltersdorf T, Elmore SW, Shoemaker AR, Armstrong RC, Augeri DJ, Belli BA et al. An inhibito of Bcl-2 family proteins induces regression of solid tumours. Nature 2005; 435: 677-681.

32. Tang TT-L. The Forkhead transcription factor AFX activates apoptosis by induction of the BCL-6 transcriptional repressor. J Biol Chem 2002; 277: 14255-14265.

33. Tait SW, Parsons MJ, Llambi F, Bouchier-Hayes L, Connell S, Munoz-Pinedo C et al. Resistance to caspase-independent cell death requires persistence of intact mitochondria. Dev Cell 2010; 18: 802-813.

34. Ricci JE, Gottlieb RA, Green DR. Caspase-mediated loss of mitochondrial function and generation of reactive oxygen species during apoptosis. J Cell Biol 2003; 160: 65-75.

35. Ricci JE, Munoz-Pinedo C, Fitzgerald P, Bailly-Maitre B, Perkins GA, Yadava N et al. Disruption of mitochondrial function during apoptosis is mediated by caspase cleavage of the p75 subunit of complex I of the electron transport chain. Cell 2004; 117: 773-786.

36. Waterhouse NJ, Goldstein JC, von Ahsen O, Schuler M, Newmeyer DD, Green DR. Cytochrome $c$ maintains mitochondrial transmembrane potential and ATP generation after outer mitochondrial membrane permeabilization during the apoptotic process. J Cell Biol 2001; 153: 319-328.

37. Scott CL, Schuler M, Marsden VS, Egle A, Pellegrini M, Nesic D et al. Apaf-1 and caspase9 do not act as tumor suppressors in myc-induced lymphomagenesis or mouse embryo fibroblast transformation. J Cell Biol 2004; 164: 89-96.

38. Min J, Kyung Kim Y, Cipriani PG, Kang M, Khersonsky SM, Walsh DP et al. Forward chemical genetic approach identifies new role for GAPDH in insulin signaling. Nat Chem Biol 2007; 3: 55-59.

39. Baba T, Kobayashi H, Kawasaki H, Mineki R, Naito H, Ohmori D. Glyceraldehyde-3phosphate dehydrogenase interacts with phosphorylated Akt resulting from increased blood glucose in rat cardiac muscle. FEBS Lett 2010; 584: 2796-2800.

40. Huang Q, Lan F, Zheng Z, Xie F, Han J, Dong L et al. AKT2 suppresses GAPDH mediatedapoptosis in ovarian cancer cells via phosphorylating GAPDH at threonine 237 and decreasing its nuclear translocation. J Biol Chem 2011; 286: 42211-42220.

41. Lindemann RK, Newbold A, Whitecross KF, Cluse LA, Frew AJ, Ellis L et al. Analysis of the apoptotic and therapeutic activities of histone deacetylase inhibitors by using a mouse model of B cell lymphoma. Proc Natl Acad Sci USA 2007; 104: 8071-8076.

42. Chen $\mathrm{C}$. Okayama $\mathrm{H}$. High-efficiency transformation of mammalian cells by plasmid DNA. Mol Cell Biol 1987; 7: 2745-2752.

43. Connors SK, Balusu R, Kundu CN, Jaiswal AS, Gairola CG, Narayan S. C/EBPbetamediated transcriptional regulation of bcl-xl gene expression in human breast epithelial cells in response to cigarette smoke condensate. Oncogene 2009; 28: 921-932.

\section{Supplementary Information accompanies this paper on Cell Death and Differentiation website (http://www.nature.com/cdd)}

